\title{
Erratum to: Researching Quality in Care Transitions
}

Karina Aase, Justin Waring and Lene Schibevaag

\section{Erratum to:}

Researching Quality in Care Transitions. International Perspectives DOI 10.1007/978-3-319-62346-7

The affiliations of Karina Aase and Lene Schibevaag were incorrect. The correct information is given below:

Karina Aase

SHARE, Department of Health Studies

University of Stavanger

Stavanger, Norway

Lene Schibevaag

SHARE, Centre for Resilience in Healthcare

Department of Health Studies

University of Stavanger

Stavanger, Norway

This has been corrected in all the occurrences throughout the book.

The updated original online version for this book can be found at DOI 10.1007/978-3-319-62346-7

(C) The Author(s) 2017

K. Aase, J. Waring (eds.), Researching Quality in Care Transitions,

DOI 10.1007/978-3-319-62346-7_16 
Karina Aase

SHARE, Centre for Resilience in Healthcare

Faculty of Health Studies

University of Stavanger

Stavanger, Norway

Lene Schibevaag

SHARE, Centre for Resilience in Healthcare

Faculty of Health Studies

University of Stavanger

Stavanger, Norway

Justin Waring

Centre for Health Innovation, Leadership and Learning Nottingham University Business School

Nottingham, United Kingdom 